\title{
PERMITTING SIGNIFICANT HARM IN THE CONSERVATION OF HERITAGE ASSETS: CONFLICTS IN SUSTAINABLE LAND-USE PLANNING DECISIONS
}

\author{
HAZEL ANN NASH \\ Centre for Engineering and the Built Environment, Birmingham City University, UK
}

\begin{abstract}
Despite the increasingly divergent legislative framework for land use planning in England and Wales, both planning regimes are characterised by a commitment towards action and decision-taking by public bodies which contribute towards sustainable development (s.39, Planning and Compulsory Purchase Act 2004). The purpose of this is to ensure that the development and use of land facilitates economic, social and environmental progress for present and future generations. The conservation of heritage assets, in a manner appropriate to their significance, forms part of the core planning objectives upon which decisions should be made. However, assessing proposals for the repurposing of built historic assets with sustainable development principles can result in decisions which not only conflict with other aspects of sustainable development, but indeed run counter to it and its protection. This paper examines the implementation of law and policy by local authorities in appraising planning applications concerning the conversion of listed buildings. The article begins by considering the underpinning legal and policy contexts in relation to sustainable development and built heritage in England and Wales. Second, it discusses the duties on decision takers in assessing the merits of planning proposals and the discretionary character of the regimes. Last, drawing on two relevant and recent planning decisions, one of which the author, engaged as the Planning Officer was responsible for evaluating, the paper examines the application of the presumption in favour of sustainable development in proposals which seek to conserve listed buildings. The paper concludes that there is a tangible risk that prioritising the long-term conservation of listed buildings at the expense of other aspects of sustainable development and wider land use planning priorities could result in perverse and harmful outcomes to listed building themselves and to economic, social and environmental progress.
\end{abstract}

Keywords: conservation, decision-taking, enabling development, harm, heritage, planning considerations, policy, sustainability, viability.

\section{INTRODUCTION}

The presumption in favour of sustainable development in the planning systems of England and Wales was introduced under s.39 of the Planning and Compulsory Purchase Act (PCPA) 2004. The PCPA 2004 provides that individuals or bodies to which the Act applies "must exercise the function with the objective of contributing to the achievement of sustainable development" [1]. A vague attempt at clarifying the effect of this provision is set out in s.39(2A) of the PCPA 2004 which explains the duty on the person or body to "have regard, in particular, to the desirability of achieving good design". A similar duty, extending only to England, was introduced by the Planning Act 2008, s. 10 which requires the Secretary of State (SoS) to exercise functions relating to the designation and review of national policy statements with the objective of contributing towards the achievement of sustainable development. Again, s.10(3) provides an indication of the requirement of the term on those carrying out public functions. In particular, the SoS must have regard to the desirability of (i) mitigating and adapting to climate change and (ii) achieving good design.

In Wales, the position of sustainable development in land use planning has been developed further in law through the Planning (Wales) Act 2015 and the Well-Being of Future 
Generations Act 2015. Indeed, sustainable development has its own part within the Planning (Wales) Act 2015. Part 2 sets out a duty on Welsh Ministers and Local Planning Authorities (LPAs) in Wales and other public bodies to exercise their function for the purpose of ensuring that the development and use of land contribute to improving economic, social, environmental and cultural well-being of Wales by carrying out sustainable development in accordance with the Well-Being of Future Generations (Wales) Act 2015. This Act sets out the meaning to be given to the sustainable development principle, echoing the Brundtland definition and drawing out specific elements a public body must take into account [2].

\section{SUSTAINABLE DEVELOPMENT AND LAND USE PLANNING}

\subsection{Law and planning policy}

Whilst the enshrinement of sustainable development in legislation should be recognised as a positive step towards embedding a consciousness of the need to balance economic, social and environmental factors in decision-making, its effectiveness depends upon its ability to be translated from legal principle to practical application. Consequently, it is only where conditions of sustainability are drawn out from the definition of sustainable development that such a duty can truly be affected [3]. This is where the National Planning Policy Framework (NPPF) for England and Planning Policy Wales (PPW) in Wales play a critical role.

The NPPF is a material consideration in determining planning applications. It establishes a presumption in favour of sustainable development. The NPPF was originally introduced in 2012 and was most recently revised in February 2019. This latest iteration has resulted in a dilution to the role of sustainable development in land-use planning. The revised NPPF, recognises three dimensions to the role of sustainable development - economic, social and environmental - which are considered in the revised NPPF (hereafter the NPPF) as needing to be pursued in "mutually supportive ways" [4]. The role of planning in the conservation and enhancement of the historic environment is recognised in the NPPF. The policy explains: "[t]hese assets are an irreplaceable resource and should be conserved in a manner appropriate to their significance, so that they can be enjoyed for their contribution to the quality of life of existing and future generations" [4]. Likewise in Wales, PPW acknowledges the important contribution historic assets can make to sustainable development objectives. In assessing the sustainable benefits of development key factors to consider include: (i) whether or not the development protects assessed assets of cultural and historic significance and (ii) whether high standards of restoration, remediation and beneficial after uses will be achieved [5].

The implementation of sustainable development strikes at the plan and decision stages of the planning system with paragraph 11 of the NPPF setting out how this is considered. Similarly, PPW recognises the role the planning system has in securing sustainable development, emphasising the importance of an effective and efficient planning system: "A well functioning planning system is fundamental for sustainable development" [5].

\subsection{Planning decision-making}

For the purposes of determining planning applications, the PCPA 2004, s.38(6) establishes that decisions should be made in accordance with the development plan unless material considerations indicate otherwise. In Wales, PPW highlights the dominance of a plan-led system, commenting that it is "the most effective way to secure sustainable development through the planning system" [5]. Again this emphasises that in the first instance, planning decisions should be determined on the basis of the policies set out within the development 
plan and that this would only accord less weight in favour of other material considerations such as national policy where the adopted development plan is outdated for the purposes.

Planning applications which reflect the policies in the development plan should be permitted without delay however, there may be instances where material considerations indicate a departure from the development plan. It is this element of the duty that affords the planning system its discretion, particularly as material considerations are not exhaustively identified. The weight to apportion to material considerations was resolved in $R v$ Swale District Borough Council, ex parte Royal Society for the Protection of Birds [1991] to be an administrative decision [6]. Inevitably, the effect of this is to enable uncertainties and inconsistent decision-making to be reasoned through differentiated weights apportioned to material considerations and discrepancies in the interpretation of relevant policies. This does little to ameliorate public confidence regarding the fairness of planning decisions [7].

Earlier research undertaken by the Land Use Consultants found that LPAs are generally uncertain about how to interpret planning policies and as a result both development plans and planning decisions are "primarily dependent upon the way in which they were perceived, used and understood by local authority officials, elected members and planning inspector" [8]. This characteristic of planning policy was observed by Schiemann $\mathrm{J}$ in $R v$ Leominster District Council, ex parte Pothecary [1998] where he remarked that each side will "be able to cite different policies in the same or different plans in support of their own contentions. In many cases the relevant policies will contain within themselves value judgements upon which reasonable persons may differ". In this way, the flexibility and discretion embedded with the planning system facilitates the decision-maker to reach an intra vires decision, applying these policies and balancing relevant material considerations.

Durnil (1999) observed that we can agree or disagree on planning decisions that are made, but "we must not lose sight of how decisions are made" [9]. Understanding the decision-making process is key, particularly in public functions such as land use planning, since the ability to challenge decisions rests on elements associated with irrationality, illegality or procedural impropriety [10]. Additionally, such an understanding assists with policy developments and insight into the implementation and interpretation by decision-makers of their statutory duties and policy objectives. Auld LJ recognised the challenges associated with planning decisions and dismissed the view that such an undertaking was merely an administrative process [11].

\section{HERITAGE ASSETS IN THE PLANNING BALANCE}

\subsection{The significance of heritage assets}

In determining planning applications, paragraph 11 of the NPPF directs LPAs to take account of (i) the desirability of sustaining and enhancing the significance of heritage assets and putting them to viable uses consistent with their conservation; (ii) the positive contribution that conservation of heritage assets can make to sustainable communities including their economic vitality and (iii) the desirability of new development making a positive contribution to local character and distinctiveness. The first element under this policy for decision-takers to grapple with is the significance of the heritage asset. The determination of a planning application regarding proposals affecting a heritage asset will be centred around an evaluation regarding the structure's significance. In Wales, PPW paragraph 6.7 explains "It is important that the planning system looks to protect, conserve and enhance the significance of historic assets. This will include consideration of the setting of an historic asset which might extend beyond its curtilage. Any change that impacts on a historic asset to its setting should be 
managed in a sensitive and sustainable way". It is clear however, that PPW underlines that a proportionate assessment should be undertaken based upon the significance of the assets and their heritage value. Technical Advice Note 24 sets out that to understand the heritage value an assessment of the significance of the historic asset that will be affected must be undertaken" [12]. This duty to judge, using all available evidence, rests with the decision-maker who should provide reasons in the Decision Notice, as required under s.24 of the Town and Country Planning (Development Management Procedure) (Wales) Order 2012, where the application is either refused or is permitted subject to conditions.

\subsection{Harm to Heritage Assets}

Paragraph 193 of the NPPF requires LPAs to identify the significance of a heritage asset (including any contribution made by their setting) and to evaluate the impact of the proposed development on the significance of a designated heritage asset with greater weight being given to the asset's conservation: "[W]hen considering the impact of a proposed development on the significance of a designated heritage asset, great weight should be given to the asset's conservation. The more important the asset, the greater the weight should be" [4].

Ultimately, the conclusion reached in planning policy for England is to adopt a two-tier approach to assessing the suitability of a proposal against the harm to the asset, depending upon its categorisation. Both tests in England and Wales adopt a high threshold of harm, referred to as "substantial harm or loss", which by the phraseology, excludes proposals which merely harm a heritage asset. Consequently, substantial harm to Grade II listed buildings, parks and registered gardens should be exceptional whilst substantial harm to assets of the highest significance should be wholly exceptional. This has the effect of raising a presumption in favour of refusing planning permission for planning applications where the impact of the proposal on a significant heritage asset will result in substantial harm or loss.

In converse, where a development proposal will lead to less than substantial harm to the significance of a designated heritage asset, planning policy directs the decision-maker to weigh the harm against the public benefits of the proposal, including securing its optimum viable use [4]. The discretionary nature of the planning system requires decision-takers to consider each planning application on its own merits. The implementation of this case by case approach, as seen above, depends upon not only the decision-takers, but also the flexibility of the policies. The policies relating to the conservation of significant heritage assets are a fine example of this. The policies in England and Wales, although separate, are clear in their ability to be interpreted differently, to be tailored to a specific proposal, building, location and wider context. Indeed, PPW paragraph 6.1.11 acknowledges this characteristic, stating that " $[\mathrm{t}]$ he application of planning and listed building controls should recognise the need for flexibility where new uses have to be considered in order to secure a building's survival or provide it with a sound economic future". To an undetermined extent, this has the effect of highlighting in the determination the influence of viability of the proposal in terms of both the likelihood of the works being carried out to specification and completed as well as achieving sustainability in the long term [13].

Whilst viability assessments are not usually required for individual applications, the Ministry of Housing, Communities and Local Government has published guidance on viability which provides that a site would be considered to be viable where the value generated by its development exceeds the cost of developing it and also provides sufficient incentive for the land to come forward and the development to be undertaken. With heritage assets, viability is particularly influential since works to these structures tend to be more expensive by virtue of their sensitivities. This can be challenging for applicants seeking to 
bring forward proposals involving and securing the future of heritage assets. The heritage asset, its condition and location and the costs associated with its repurposing will be reflected in the development proposal, its magnitude and type. The Guidance on Viability advises in paragraph 17 that the viability assessment should be based on current costs and values. Planning applications should be considered in today's circumstances [13].

Similarly in Wales, the aim of planning policy for historic buildings is to "find the best way to protect and enhance the special qualities of listed buildings, retaining them in sustainable use" with the continuation or reinstatement of the original use being the preferred option [5]. Where this is not viable PPW provides that adaptation of historic buildings should be informed by careful assessment and allow for proper evaluation of the benefits of intervention and the impact on the special architectural and historic interest. Underlying this policy is an acute consideration of the statutory requirement contained in the Planning (Listed Building and Conservation Areas) Act 1990, s.16(2) to have special regard to the desirability of preserving the building, its setting or any features of special architectural or historic interest. The policy intention in PPW is to safeguard the character of historic buildings and manage their change so that their special architectural and historic interests are preserved.

Despite the ostensibly stringent policy in PPW, the policy introduces a test for enabling development. This describes the circumstances in which development which runs contrary to objectives in national or local planning policy may be appropriate on the basis of substantial heritage benefits. Paragraph 6.1 .31 of PPW explains that "[s]uch development may be appropriate if the public benefit of rescuing, enhancing, or even endowing an important historic asset decisively outweighs the harm to other material interests". Acceptability of enabling development has been teased out in a separate guiding document published by the Welsh Government's historic environment service, Cadw, entitled "Conservation Principles" [14]. Similar to the NPPF in England, this document emphasises that decisions should be proportionate to the public benefit the proposal offers. In terms of applying the conservation principles established in the document, the advice is pragmatic and echoes that contained within the NPPF: "Every reasonable effort should be made to eliminate or minimize adverse impacts on historic assets. Ultimately, however, it may be necessary to balance the benefit of the proposed change against the harm to the asset. If so, the weight given to heritage values should be proportionate to the importance of the assets and the impact of the change upon them" [14]. Even then, planning permission should only be granted if the achievement of the heritage objective is securely and enforceably linked to the enabling development [5].

This paper will now turn to consider two recent planning decisions involving heritage assets. First, Old Court Brobury in England and second Troy House in Wales. The former was determined prior to the revision of the NPPF and accordingly, the policy relied upon was that contained in the NPPF (2012) and the development plan. These studies are drawn upon as the author has been involved with both of them, albeit in different capacities. With the former, the author acted as the Local Authority Planning Officer and in the latter the author provided advice to an individual objecting to the proposal.

\section{CASE STUDIES}

\subsection{Case Study 1: Planning Application at Old Court, Brobury, Herefordshire}

This application, dealt with by the author in her previous role as Planning Officer, sought planning permission and Listed Building Consent for the conversion of a Grade II listed barn and Granary Annex into two residential dwellings. The buildings proposed for conversion formed part of a site comprising of six buildings around a traditional farm courtyard, accessed 
via a private track serving the farm and a separate Grade II listed building to the south. The river Wye runs approximately $500 \mathrm{~m}$ west of the site. The site is located approximately 8 miles northeast of Hereford on the fringes of Brobury. Brobury is not identified in the development plan as a settlement for housing growth and therefore the site is considered to be in open countryside [15]. Policy SS2 of the Herefordshire Core Strategy directs that Hereford and the market towns shall be the main focus for new housing development with support for proportionate growth of sustainable rural settlements listed in two tables.

Essential to the determination was the principle of the proposal to convert the listed buildings into residential accommodation. Despite the steer away from new development in open countryside, the Herefordshire Core Strategy, as the development plan, identifies certain situations in which such development can be supported outside of settlements. Policy RA3 bullet point 4 of the Strategy provides that a development proposal can be supported where it "would result in the sustainable re-use of a redundant or disused building, complies with Policy RA5 and leads to an enhancement of its immediate setting". Policy RA5 sets out criteria which a proposal for the sustainable reuse of redundant or disused buildings, including farmsteads in rural areas should satisfy in order to be capable of being permitted. Therefore, provided that the application demonstrates that the proposal addresses these points, the development plan establishes a presumption in favour of development.

The application attracted 36 public objections concerning a number of issues. Due to the number of representations, the application was redirected to the Planning and Regulatory Committee of the Local Authority for determination. The Committee considered the proposal on 15th November 2017. The Officer's recommendation to Committee was to approve with conditions the proposal. The basis for this was that the proposal was considered to result in less than substantial harm to the listed buildings as provided under paragraph 134 of the NPPF. The advice from Historic England and the Building Conservation Officer in ascertaining whether the development proposal would lead to substantial harm or to total loss of significance of the heritage asset was pivotal in this regard. Historic England raised no objection to the amended plans, considering their earlier concerns to have been addressed [16]. They recommended that the application be determined in accordance with national and local policy guidance and on the basis of the local authority's expert conservation advice. The impact of the proposal on the listed building, the extent and magnitude of any harm fell predominantly to the Service Manager for Built and Natural Environment, referred to as the Building Conservation Officer (BCO), to assess and advise on [17]. Following the submission of amended plans, the BCO supported the proposal subject to conditions stating that the less than substantial harm the proposals would cause to the setting of the nearby listed buildings and the character of the conservation area is mitigated by the public benefit of housing provision and as such accords with policy contained in the NPPF (2012) paragraphs 131, 132, 134 and Herefordshire Council's Core Strategy, particularly policies LD4 and RA5.

Accordingly, the advice from the BCO was that in terms of the impact on the listed buildings, the proposal constituted less than significant harm. The then paragraph 134 of the NPPF directs that where there is "less than substantial harm to the significance of a designated asset, the harm should be weighed against the public benefit of the proposal". This has the effect of directing a refusal of planning permission where public benefit, including securing an optimum viable use, does not outweigh the harm to the building. In this instance the balancing exercise considered the proposals to be sympathetic to the listed buildings and their setting and a viable method of long-term protection and conservation of the buildings, relying on the comments from the BCO. In addition, the re-use of the buildings as residential accommodation was considered to represent a public benefit in terms of contributing to housing supply. In factoring in the non-heritage impacts in the normal planning balance, 
ecological impacts and transport were considered in view of the advice received from the Ecologist and Transport Manager respectively. Both of which were satisfied that any adverse impacts could be addressed by way of conditions attached to the permission [18]. As a result, in the exercise of planning judgement it was considered that there were no adverse impacts identified which were considered to significantly or demonstrably outweigh the benefits associated with securing the long term protection and conservation of the Grade II heritage assets and the wider setting of Old Court, Brobury [19]. Following this, under the normal planning balance and weighing all other non-heritage material considerations, the proposal was considered to satisfy paragraph 14 of the NPPF (2012) (now paragraph 11 under the NPPF 2019), resulting in the Case Officer's conclusion that the proposal complied with relevant planning policy and all other material considerations.

The proposal clearly touched upon a number of elements within the concept of sustainable development. It then falls to the decision-taker to weigh these factors and all other material considerations in order to arrive at a determination. Critical to such a decision are the comments, information and advice provided by consultees which assist in the application of policy against the proposal. Ultimately, the presumption in favour of sustainable development can be construed in a variety of ways, integral to this is the planning balance where material considerations are weighed in order to draw down a recommendation. As can be seen from this example, this balancing can be complex and intricate, requiring the flexibility of the planning system and guided by representations and the application of relevant planning policies and other material considerations. Proposals which demonstrate a thorough appreciation and understanding of a heritage asset and sympathetic design as well as a willingness to work with the LPA has greater chance of a having a successful outcome. It should be noted that this application evolved from earlier versions proposing conversion of buildings on the site [20]. Notably, proportionate development appears to have been important, on the basis that the impact on the heritage asset was not considered to be substantial, this differs from earlier renditions which sought to provide five dwellings at the site (Applications P162794/F and P162799/L were withdrawn) and received a number of objections with Historic England describing the proposal as "intensive residential use" which will "diminish the significance of the listed group as a whole" [21]. Equally absent was the driver of viability which, as will be seen in the second case study, can be highly influential in terms of the proposal and the extent of interference with the historic asset and its features.

\subsection{Case Study 2: Planning Application Troy House, Mitchell Troy, Monmouthshire}

The proposal at Troy House, a Grade II* late 17th century manor house involved two elements (i) the conversion of the listed building into 23 luxury apartments and (ii) the construction of two new wings to the building providing a further 31 new luxury apartments. The building, located to the southeast of Monmouth, in the open countryside, sits within a Historic Park and Garden and within the Wye Valley Area of Outstanding Natural Beauty (AONB). The site is situated on undefended flood plain, identified in Technical Advice Note 15: Flood Risk as a C2 flood zone [22]. The application was submitted in June 2008 and taken to Committee first on June 6, 2017 with recommendation to refuse on the grounds of insufficient information [23]. Following the submission of additional information required by the Committee, the application was approved with conditions on February 6th 2018 by the Planning Committee reflecting the Officer's refreshed recommendation which concluded: "It is considered that this recommendation is in accordance with the sustainable development principle through its contribution towards one or more of the Welsh Minister's well-being objectives set out in section 8 of the Well-Being of Futures Generation Act. This particular 
application has a number of specific constraints and concerns and significant weight has been given to ensure that the listed building is preserved and would preserve the social and cultural wellbeing of Wales in the long term by restoring a significant heritage asset" [24].

Such a conclusion is a clear departure from the development plan and indeed the local and national planning policy. PPW (2016) at paragraph 6.1.4 emphasises that following the development plan is the most effective way to secure sustainable development and therefore LPAs require good reasons if they approve a development which is a departure from the approved or adopted development plan or is contrary to the Welsh Government's stated planning policies or the advice of a statutory consultee.

Again, the principle of conversion of the listed buildings and the construction of two additional wings to the building for residential use was central to decision. Policy LC1 of the LDP establishes a presumption against new built development in the open countryside unless proposal sits within an exceptional circumstance and even then it will need to satisfy a number of criteria [24]. Indeed, Policy H4 of the adopted LDP sets out seven criteria which must be satisfied for rehabilitation of buildings in the open countryside for residential use to be supported. These include, that the proposal is of a scale and bulk which respects the rural character and design of the building and that "only very modest extensions will be allowed" in such conversions. The policy states that the criteria will be applied strictly.

The Officer's report contended that the proposal was acceptable on the basis of sympathetic design and finish reflecting the character of the original building [24]. However, representation received from Cadw and Heritage Officer comments did not clearly indicate the same conclusion. Cadw felt some of the new elements had the potential to harm the historic character of the building and its setting. Similarly, the report dismissed NRW's objection to what NRW described as "significant adverse visual effects on the AONB and registered landscape", arguing that "[a]lthough it would be beneficial for the scheme to be supported by a landscape impact assessment, the siting of the new build development is acceptable and justifiable in architectural terms". It refers to a group of mature trees on the site considered to screen the impact and concludes that the proposal complies with policy LC4 of the LDP. NRW also objected to the proposal on the ground that it failed to comply with the criteria in A1.14 of TAN15 [25]. Indeed, NRW requested that the Council review the amount of new build development but, according to the Officer, the viability assessment mitigated any downsizing of the proposal [25]. Furthermore, whilst Policy S4 of the development plan provides for provision to be made for a percentage of dwellings in a conversion development to be affordable dwellings no such requirement was made in this instance on the basis of creating an unviable development proposal.

The objective of planning policy for heritage assets in Wales is to find the best way to protect and enhance their quality and retain them in a sustainable use [26]. It is debateable whether the approval of this proposal satisfies this national planning objective on either element - the extent of physical and material change to the building and its setting will, arguably, neither protect or enhance the value of the asset or result in its sustainable use. Compellingly, even section 66 of the Planning (Listed Building and Conservation Areas) Act 1990 acknowledges the importance of conducting a balanced assessment in which all material consideration are taken into account when determining proposals to a listed building: "special regard does not and should not be interpreted as an automatic presumption in favour of development where it seeks the long term preservation of a heritage asset at the cost of all other relevant material considerations". Indeed, in the representation submitted on behalf of our clients, it was argued that when applying section 66 to the Troy House application, it was clear that the proposal should not be supported. 
Comments from Monmouthshire County Council Heritage Officer is not accessible online, although they are referred to in the Officer's Committee Report of January 2018 [24]. There is little discussion which demonstrates the Officer's evaluation of the proposal against the extent of harm to the heritage asset. It is legitimate to expect that the Officer's report contains a detailed and direct evaluation regarding the impact of the proposals to the asset balanced against the heritage value. Paragraph 6.4 of the Report provides a brief explanation of the significance of Troy House and its last use as a boarding school. The evaluation identifies the building as a significant asset recognising however that "the proposals that form part of this application...will have an impact on the internal and external significance of the building". This discussion continues by concluding "however when balanced against the issues discussed above this is considered acceptable and necessary to secure the new use for the building". Clearly then, although not directly set down in the Report is the conclusion that the heritage asset is a significant heritage asset and that the proposal has the potentially to substantially harm or impact the significant asset. Accordingly, the evaluation should then turn to the benefits of intervention and the specific impact on the special architectural and historic interest of the building [24]. It should be demonstrated that the public benefit of rescuing an important asset decisively outweighs the harm to other material interests.

In this instance, the Officer recommended the application for approval with conditions, recognising it as a departure from the development plan, in terms inter alia, of its location in the open countryside and the construction of highly vulnerable development on undefended floodplain. The Officer justified this departure from relevant planning policy on the grounds that " $[\mathrm{t}]$ he enabling development is fundamentally required in order to provide the finance to convert the listed building which is at risk" [24]. As such, substantial emphasis (and reliance) in the assessment of the proposal was placed on the 2015 viability assessment [27].

In terms of the siting of new development on $\mathrm{C} 2$ floodplain, following additional information NRW maintained its objection and raised concerns regarding the potential effects on the AONB. Policy SD3 of the development plan provides that "highly vulnerable development will not be permitted in areas which are liable to flooding". The Flood Consequences Assessment was considered by NRW to be insufficient to enable them to withdraw their objections and they also raised concern regarding the potential effects on the AONB [25]. Policy LC4 sets out that development must be subordinate to the primary purpose to conserve and enhance the natural beauty of the area. The importance of protecting the landscape value of the Wye AONB is emphasised under Policy H4 which guides decision-makers to place greater weight on design, means of access, service provision and garden curtilage where the proposal is situated within the Wye Valley AONB. Policy LC4 sets out the planning policy for the Wye Valley AONB requiring proposed development to be subservient to the primary purpose to conserve and enhance the natural beauty of the area (regard is given to: (a) compatibility with the character, purpose and management of the AONB; (b) design, quality and materials; (c) landscaping; d) protection of landscape features; (e) generation of additional traffic; (f) impact on nature). The Officer sought in his second report to Committee to justify the setting aside of flood risk concerns, harm to the setting of the listed building and landscape on the basis that the "long term preservation of the building is considered to outweigh the in principle flood risk objection and the concerns of consultees in terms of impact of the development" [24].

The Officer's report justifies the recommendation to approve the proposal and reasoned: "The approval of this application would ensure that this building of national importance can be restored and saved for future generations. The long-term preservation of the building is considered to outweigh the in-principle harm and the concerns of consultees in terms of impact of the development on the registered historic garden and the wider landscape" [24]. 
This conclusion appears to go beyond a departure from the development plans and national policy, but also places minimal weight on consultee responses including those of the NRW and Cadw. It is clear that the Officer in exercising their planning judgement has apportioned greater weight to the long-term conservation of the significant heritage asset. However, the number of adverse impacts associated with the scale of enabling development required to make it viable in this instance suggests that other elements which equally form part of sustainable development have been traded off in the interests of permitting the scheme for the listed building conversion. This raises the question at what point will public benefit and other substantial harms be given greater weight in planning decisions than the restoration of a significant asset? Particularly, when the impact on the asset itself is considered by consultees to be transformational to the character, features, architectural value or setting of the heritage asset.

\section{CONCLUSION}

Through two specific examples, this paper has sought to provide an insight into the complexities associated with balancing quite diverging components of sustainable development in the land-use planning process. Challenges for sustainable development emerge where proposals accord with some elements of the principle but conflict with others, for example repurposing heritage assets to secure their future but simultaneously increasing flood risk, exacerbating traffic movements or increasing residential occupation outside defined settlements.

The extent to which the preservation of significant heritage assets should be prioritised over and above these other sustainable development components remains, as the nature of the planning system is established, at the discretion of those conferred with statutory powers of decision-making. To this end, national guidance and the development plan are the key bolt holes for securing consistent planning decisions, although the statutory provision allows for a departure, as borne out in the Troy House case.

It has not been the intention of this paper to compare these two separate and different applications to repurpose heritage assets. Indeed, it would be erroneous to do so. Despite them having some elements in common, there are substantial differences between them, including the scale of proposed development and the jurisdiction for the purposes of relevant law and policy. Moreover, the author, as the Development Management Officer for the Old Court application would clearly be preferential to her own determination. The discretion afford in the planning system facilitates the balancing of material considerations which may often be in conflict or create tensions which the determining officer is responsible for evaluating. Consequently, within the limitations of the duties conferred by statute, it is possible for Planning Officers to reach different decisions based upon the same material considerations [28].

A number of observations regarding the balancing of significant heritage assets and other material considerations can be drawn from the above analysis. First, policies in relation to heritage assets are complex to apply in practice. Determining significant harm is a value judgement and relies upon expert advice from relevant statutory consultees and in-house Building Conservation Officers. This will be considered on the merits of each case but, as section 66 of the Planning) Listed Building and Conservation Areas) Act 1990 sets out, works to listed buildings for preservation and conservation should not be undertaken at all costs. Therefore, the Officer's approval recommendation for Troy House loses credence. At the point there is "transformation" [29] of a building, the heritage asset surely ceases to exist?

The extent of proposed works must therefore be influential to the decision. The greater the scale of interference with the heritage asset, the more likely that significant harm will be 
done. In the proposals for Old Court, Brobury, the scale of the alterations was a determining factor for the Building Conservation Officer in advising on the capability of supporting the proposals in accordance with national and local policies. As a result, the original proposal was substantially reduced in scale and intensification. However, viability was not a factor in the determination, whereas in Troy House the Officer placed weight on the viability of the proposal under the enabling development policy in PPW. The inclusion of viability into development proposals is not always conducive to the preservation or conservation of significant heritage assets. This is because extensive repairs and renovations to convert and/or repurpose a redundant or disused building is by virtue of the nature and importance of the building more expensive, often requiring specialist materials or building and construction techniques. Consequently, in order for these types of schemes, particularly those larger schemes, the greater the need for applicants to satisfy themselves that they will receive a return upon completion of the project. Furthermore, the greater the need should be that Planning Officers are content that the applicant will see the project through. The trade-off provided with viability assessments is that damage will occur to heritage assets in order for those assets to be provided with an opportunity to be resurrected for use today.

A further observation is that such determinations are reliant on accurate and up-to-date information. Indeed, the NPPF recognises this in paragraph 192: "The right information is crucial to good decision-taking". Therefore, decision-makers should satisfy themselves they have the level of information and advice they require to assess the proposal and where statutory consultees request further information to evaluate the proposal this should be required, and the consultee satisfied sufficiently to remove any objection to the proposal.

In addition, the evolution of proposals can be difficult to follow by those on the outside of the system. This can be further confused through, for example, delay in uploading comments or progress on the application to the website, poorly labelled files in the public domain, acceptance of amended plans without re-consultation and delays in decision-making. It is little wonder that the planning system has a poor public reputation when the process can be impenetrable and complex to follow. Indeed, the application at Troy House is muddied by the length of time and volume of documents associated with its evolution over the past 9 years. It is therefore not surprising that the decision to approve the planning application and grant listed building consent for the proposed development at Troy House is at the time of writing before the Welsh Ministers for reconsideration.

Lastly, it is unlikely that any decision will satisfy all interested parties. This is the nature of land-use planning. Consequently, it is the responsibility of the determining Officer to ensure they have all relevant information, that they have followed the statutory procedures prior to making a decision and that they have provided reasons for the decision in adequate detail which demonstrates that all material considerations have been taken into account and how they have been balanced against each other to reach the decision to approve or refuse.

\section{ACKNOWLEDGEMENTS}

I would like to thank Herefordshire Council for supporting my academic work and understanding the value of practice-based teaching and Karen Anthony, Solicitor at Agriadvisor for the boundless humour and endless phone calls as we endured the twists and turns with Troy House.

Planning and Compulsory Purchase Act 2004, Part 2 and Part 6.

[2] World Commission on Environment and Development, Our common future. United Nations, para 27, 1987. 
[3] Conroy, C. \& Litvinoff, M. (eds), The Greening of Aid: Sustainable Livelihoods in Practice, Earthscan: London, 1988.

[4] Ministry of Housing, Communities and local government, National Planning Policy Framework, MHCLG, para 8, 2019.

[5] Welsh Government, Planning policy Wales, Cardiff, 2018.

[6] R v Swale District Borough Council, ex parte Royal Society for the Protection of Birds, [1991].

[7] Beaufort Research and Welsh Government, Public Attitudes towards the planning system in Wales. Welsh Government, June 2012.

[8] Durnil, G.K., How much information do we need before exercising precaution? Protecting Public Health and Environment: Implementing the Precautionary Principle, eds C. Raffensberger \& J.A. Tickner, Island Press: Washington, 1999.

[9] Land Use Consultants, Effectiveness of planning policy guidance notes, HMSO: London, 1995.

[10] Council of Civil Service Unions v Minister for the Civil Service [1985] 1 AC 374.

[11] R v Derbyshire County Council, ex parte Woods [1997] Env LR 277 at 22.

[12] Technical Advice Note 24, para 1.12.

[13] Ministry of Housing, Communities and Local Government, Guidance: viability. MHCLG: London, 2014.

[14] Cadw and Welsh Government, Conservation principles for the sustainable management of the historic environment in Wales, Cadw and Welsh Government. Cardiff, 2011.

[15] Herefordshire Council, Herefordshire local plan core strategy 2011-2031, Hereford, October 2015.

[16] Historic England, Comments, 10/08/2017.

[17] Consultee, Memorandum, 22/08/2017.

[18] Consultee Ecology, Email re: Old Court Brobury, 10/08/2017.

[19] Herefordshire Council, Committee report: Old Court Brobury, 15/11/2017.

[20] Planning Application P162794/F and P162799/L.

[21] Historic England West Midlands Office, Letter to Herefordshire Council re. application No. 162799, 26/10/2016.

[22] Technical Advice Note 15: Flood risk.

[23] Monmouthshire County Council, Officer's report to committee, June 2017.

[24] Monmouthshire Country Council, Officer's report to committee, February 2018.

[25] Natural Resources Wales, Reconsultation comments: Troy House, 09/01/2018.

[26] Agri Advisors, Representation objecting to planning application DC/2008/00723 \& DC/2008/00724, 2018.

[27] Timbershore Ltd, Troy House: Preliminary viability appraisals, November 2015.

[28] Civil Procedure Rules Part 54 and 54A.

[29] Pugh, D., Troy House Saved as Planners Flout Flood and Access Concerns, Monmouthshire Beacon. 